\title{
THE ROLE OF PEPSINOGENS IN THE FORMATION OF GERD IN PATIENTS WITH COPD
}

\author{
Olesia Liakh \\ Ph.D., Assistant Professor, Uzhhorod National University, Ukraine \\ e-mail: olesya.lyakh@uzhnu.edu.ua,orcid.org/0000-0003-1539-5407
}

Marianna Tovt-Korshynska

Doctor of Medical Sciences, Professor, Head of the Department of Internal Medicine,

Uzhhorod National University, Ukraine

e-mail: tovtkm@gmail.com,orcid.org/0000-0002-8763334X

\begin{abstract}
Summary
The article presents data on the role of pepsinogen- 1 and -2 and bilirubin in the formation of gastroesophageal reflux disease (GERD) in patients with chronic obstructive pulmonary disease (COPD). Clinical, biochemical, immunological research methods were used in the work. The activity of pepsinogens 1 and 2 and bilirubin in saliva was determined in all patients with combined pathology. It has been established that the presence of concomitant GERD in patients is an independent aggravating factor for the function of external respiration. In patients with concomitant GERD, a significant increase in acute phase parameters in the serum, indicating active systemic inflammation. Increased activity of the cytokine IL- 6 and IFN $\gamma$ indicates the activation of the cellular immune system, with an unregulated immune response that supports chronic inflammation in the bronchi even in remission. Increased levels of IL-4 are compensatory in nature, as IL-4 inhibits the production of macrophages of proinflammatory cytokines, including IL-6. Detection of correlations between the concentration of total bilirubin in saliva with a decrease in external respiration, namely FVC, FEV-1, as well as the presence of shortness of breath allows us to consider bilirubin as a possible marker of reflux and respiratory inflammation in the bronchi, until obstruction. The positive correlation of pepsinogen-1 in saliva with an allergic history, and pepsinogen- 2 in saliva with cough, shortness of breath and smoking, and a negative correlation of pepsinogen-1 with the value of FEV1 / FVC, allows to consider pepsinogen-1 and pepsinogen-2 as markers of non-acid reflux and respiratory inflammation with bronchoobstruction
\end{abstract} acid reflux.

Keywords: pepsinogen-1, bilirubin, saliva, chronic obstructive pulmonary disease, nonDOI: https://doi.org/10.23856/4822

\section{Introduction}

In the general structure of morbidity, a significant percentage of all diseases are respiratory diseases. According to general data, their share is about 60\% (Chorna et al.,2020). This is due to the increase in the number of non-specific lung diseases, and is particularly noticeable in the growing number of patients with chronic obstructive pulmonary disease (COPD). According to the WHO, COPD is a disease with a high level of social burden (Tolokh,2017]. The progression of COPD is accompanied by the development of pathological processes in various 
organs, including the digestive system. The presence of concomitant pathology in patients with COPD increases the risk of exacerbations, hospitalizations and disabilities, reduces their activity, impairs quality of life and survival, and therefore has important prognostic value (Golpe at el.,2017). Gastroesophageal reflux disease (GERD) is one of the most common gastrointestinal diseases in the general population. The prevalence of GERD in the population is determined in the range of $7-20 \%$, in Western countries - varies on average between $10 \%$ and $25 \%$. The issue of comorbidity of chronic obstructive pulmonary disease with gastroesophageal reflux disease as an interdependent pathological condition is attracting increasing attention. These diseases are combined in $25-60 \%$ of cases (Shevchuk-Budz,2018, Lin et al. 2019). According to numerous studies, the presence of GERD is associated with a deterioration in the quality of life in this cohort of patients, worsening of symptoms, deterioration of external respiration, which leads to more frequent exacerbations of COPD (Makarova et al. 2019, Francis,2016). Occurrence of GERD in patients with COPD can be both primary-independent diseases (due to combined lesions of the mucous membranes of the respiratory and digestive systems, associated with unidirectional metabolic and allergic changes and dysregulation of the nervous, immune and endocrine systems) and as primary-dependent pathological processes (when lung obstruction with the appearance of GERD may be exacerbated by microaspiration of gastric contents into the trachea and bronchi, as well as in the process of stimulation of nervus vagus receptors of the distal part of the esophagus. On the other side, the pathology of the pulmonary system, provoking cough, leads to changes into intrathoracic pressure and, consequently, to a decrease in the tone of the lower esophageal sphincter, which is one of the pathogenic factors in the formation of GERD (Katzka et al. 2011, Aras et al., 2010).

Microaspiration of gastric contents and hydrochloric acid is just one of many factors that can cause respiratory damage. Other damaging factors may be pepsinogen, pepsin, pancreatic enzymes and bile acids / salts (Kusano et al.,2011). However, aspiration of duodenogastric contents may be accompanied not only by cough but also by acute respiratory distress syndrome. It should be noted that the upper parts of the digestive system (pharynx) and respiratory tract (larynx and bronchi) are more sensitive to reflux than the mucous membrane of the esophagus (Kravchenko et al., 2011). Laryngo-pharyngeal reflux, which is the result of the effects of various components of gastric and duodenal reflux on the mucous membrane of the pharynx, larynx and respiratory tract, is considered one of the most likely mechanisms of extraesophageal complications of GERD. (Pearson et al., 2011). The pharynx and larynx are extremely sensitive to weak acid reflux, especially in the presence of pepsin. There is no doubt that pepsin will have a greater detrimental effect on the respiratory epithelium in acid reflux. However, the association of pepsin with inflammation of the laryngeal epithelium in non-acidic forms of GERD has been observed even in patients taking high doses of Proton pump inhibitors (PPIs). It was previously thought that pepsin causes damage only because of its proteolytic activity. However, further studies have shown that pepsin is captured by laryngeal epithelial cells by endocytosis. (Wang et al., 2020). It shows a new mechanism of cell damage, which involves the development of new treatments for reflux disease, namely use of receptor antagonists and / or pepsin inhibitors (Ye et al., 2017).

The above data provide clear evidence for the role of GERD in the development of chronic obstructive pulmonary disease, but there are still many controversial and unresolved issues. The mechanisms of development and pathogenesis of these two diseases, diagnostic methods, rational schemes of drug therapy continue to be actively discussed.

The need for in-depth study of the pathogenic mechanisms of parallel development of COPD and GERD diseases (with determination of the activity of the cytokine system) determines the scientific and practical relevance of this study. 
The aim of research was to establish the pathogenic mechanisms of obstructive pulmonary disease with gastroesophageal reflux disease.

Materials and methods of research. The observation included 138 patients who were hospitalized in the pulmonology department due to exacerbation of COPD and outpatient treatment by a gastroenterologist.

All subjects signed an informed consent, the methodology of which was in line with the Helsinki Declaration of 1975 and its revision in 1983 and was approved by Uzhhorod National University's Commission on Bioethics (Protocol №1 of 10.01.2020).

The inclusion criteria in the study confirmed the patients with exacerbation of COPD stage 2 (GOLD II), age $>40$ years, forced expiratory volume per 1 second (FEV1) was $<60 \%$ of normal and the ratio of forced expiratory volume per 1 second to forced vital capacity lungs (FEV1 / FVC ratio) $<70 \%$, increase in FEV1 after inhalation of short-acting $\beta 2$-agonist less than $12 \%$ compared to baseline.

The exclusion criteria in the study were malignancy, systemic connective tissue diseases, heart block, congenital malformations and heart failure above functional class II according to the classification of the New York Association of Cardiologists.

In turn, the diagnosis of COPD was confirmed according to the order of the Ministry of Health of Ukraine №555 from 27.06.2013 "On approval of clinical protocols for medical care in the specialty" Pulmonology "and the provisions set out in the document GOLD [2017]. The diagnosis of gastroesophageal reflux disease (GERD) was made in the presence of relevant complaints and the results of instrumental studies - a positive test with rabeprazole, fibrogastroduodenoscopy (FGDS) and intragastric pH-metry, taking into account the Montreal Consensus (2006), as well as in accordance with domestic protocols for medical care (order of the Ministry of Health of Ukraine № 943 of 31.10.2013).

We formed 3 groups of patients: 1 group $(n=60)$ - patients with COPD in combination with GERD, 2 group $(n=42)$ - patients with COPD without signs of GERD, who were treated in the pulmonology department for exacerbation of the disease and Group $3(n=36)$ - patients with GERD who were treated on an outpatient basis. Patients were homogeneous in age, stage of disease and duration of illness. The mean age of the subjects was $55 \pm 1.64$. Among the examined patients, men predominated by sex $-78.3 \%$ (108 out of 138 ).

Patients also underwent additional determination of indicators of inflammation (CRP, leukocytes, neutrophils, ESR, procalcitonin), cytokine activity (IL-4, IL-6, IFN $\gamma$, IFN $\gamma$ / IL-4, TNF-alpha and levels of pepsinogen-1, pepsinogen-2 and bilirubin in saliva.

Statistical analysis of the data was performed using Jamovi, version 2.0.0 using the paired Student's t-test, Pearson's $\chi^{2}$ - test and Fisher's exact test, depending on the type of source data. The average values of the numerical data were represented as $\mathrm{M} \pm \mathrm{SD}$. The normality of the distribution was evaluated by the Shapiro-Wilk test. The critical level of reliability was considered to be $\alpha=0.05$.

\section{Results}

The clinical characteristics of patients with combined pathology (COPD with GERD) were evaluated, and 60 patients (48 men and 12 women) were selected. In the age range, patients from 44 to 59 years were examined, the average age was $55 \pm 1.64$ years (women $57 \pm 0.9$ years, and men $-54 \pm 1.2$ years).

The main symptoms of the disease were respiratory symptoms, namely shortness of breath in 59 of 60 patients $(98.3 \%)$ and cough in 57 of 60 patients $(95.0 \%)$. Shortness of breath occurred 
during exercise in 49 of $60(81.7 \%)$ patients, and at rest in 11 of 60 (18.3\%), respectively, at $p<0.05$. The most common type of cough was unproductive - in 30 of $60(51.7 \%)$ patients, which worsened when changing body position from horizontal to vertical and when eating, the intensity was the same during the day. The presence of sputum was detected in 43 of $60(71.7 \%)$ patients. Macroscopic examination of sputum was mucous, viscous, white in 17 of $60(28.3 \%)$ patients, which caused difficulty in coughing. A feeling of tightness in the chest with the inability to fully exhale was found in 40 of $60(66.6 \%)$ patients. Patients were also concerned about complaints of difficulty breathing, especially at night with increased shortness of breath in 38 out of $60(63.3 \%)$ patients, weakness and decreased tolerance to exercise, which limited the ability to work in 52 out of $60(86.6 \%)$ patients. Chest pain, which worsened after coughing, had 18 of $60(30 \%)$ patients.

In patients with COPD and GERD, gastroenterological symptoms were dominated by heartburn in 30 out of $60(50 \%)$ and / or acid regurgitation in 33 out of $60(55.5 \%)$, sorethroat in 31 out of $60(51.6 \%)$, cases of patients at $p<0.01$, as well as dysphagia in 28 of $60(46.6 \%)$ cases of patients at $p<0.05$. Extraesophageal manifestations of GERD were detected in 26 of $60(43.3 \%)$ patients with COPD, manifested by sorethroat in 7 of $60(11.6 \%)$, hoarseness in 4 of $60(6.6 \%)$, unproductive cough, which is exacerbated at night in 14 of $60(23.3 \%)$, chest pain in the esophagus and heart failure in 2 of 60 (3.3\%).

A positive family history of allergy was found in 19 out of $60(31.7 \%)$, women - in 4 out of $60(6.7 \%)$, men - in 15 out of $60(25.0 \%)$.

51 out of $60(85.0 \%)$ patients were prone to smoking, of which 45 out of $60(75.0 \%)$ were men and 3 out of $60(5.0 \%)$ were women. Smoking experience according to the smoker index was $22 \pm 2.48$ years; in men $22 \pm 4$ and in women $21 \pm 5.3$ years, respectively.

In most patients with combined pathology, the upper limit of the BMI was exceeded in 42 out of $60(70.0 \%)$.

Table 1 presents a comparative characterization of patients with COPD and GERD and patients with isolated COPD.

Table 1

Clinical characteristics of the patients

\begin{tabular}{|l|c|c|c|c|}
\hline \multicolumn{1}{|c|}{ Parameters } & \multicolumn{2}{c|}{$\begin{array}{c}\text { group 1 (n= 60) } \\
\text { COPD + GERD }\end{array}$} & \multicolumn{2}{c|}{$\begin{array}{c}\text { group 2 (n=42) } \\
\text { COPD }\end{array}$} \\
\hline \multirow{2}{*}{$\begin{array}{l}\text { Gender } \\
\text { male / female (abs./\%) }\end{array}$} & male & female & male & female \\
\cline { 2 - 5 } & $48 / 80,0$ & $12 / 20,0$ & $32 / 76,2$ & $10 / 27,8$ \\
\hline Age (years) & $54 \pm 1,2$ & $57 \pm 0,9$ & $53 \pm 2,1$ & $56 \pm 1,6$ \\
\hline Smokers (abs /\%) & $45 / 75,0$ & $3 / 5,0$ & $30 / 71,4$ & $4 / 9,5$ \\
\hline $\begin{array}{l}\text { Smoking experience (smoker index) (years) } \\
\text { Frequency of exacerbations per year }\end{array}$ & $22 \pm 4,7$ & $21 \pm 5,3$ & $23 \pm 6,6$ & $24 \pm 3,4$ \\
\hline $\begin{array}{l}\text { Body mass index (BMI) (kg) / height (m) } \\
\text { 18.5-24.9 (abs /\%) }\end{array}$ & $10 / 16,7$ & $1 / 1,7$ & $16 / 38,1$ & $4 / 9,5$ \\
\hline $\begin{array}{l}\text { Body mass index (BMI) (kg) / height (m) } \\
\text { 25.0-29.9 (abs /\%) }\end{array}$ & $26 / 43,3$ & $6 / 10,0$ & $11 / 26,2$ & $3 / 7,1$ \\
\hline $\begin{array}{l}\text { Body mass index (BMI) (kg) / height (m) } \\
\text { more than 30 (abs /\%) }\end{array}$ & $12 / 20,0$ & $5 / 8,3$ & $5 / 11,9$ & $3 / 7,1$ \\
\hline Frequency of exacerbation per year & $2,1 \pm 0,3$ & $1,8 \pm 0,6$ & $1,7 \pm 0,4$ & $1,8 \pm 0,3$ \\
\hline Frequency of hospitalization per year & $1,7 \pm 0,3$ & $2,0 \pm 0,7$ & $1,6 \pm 0,5$ & $1,7 \pm 0,5$ \\
\hline
\end{tabular}

Note. Significance of the difference: ${ }^{*}$ - in comparison with patients of group 2 at $p<0,05$. 
When comparing groups by sex, age and smoking history, no statistically significant differences were found in patients with a combination of COPD and GERD ( $p>0.05)$. Patients with symptoms of GERD compared with patients without GERD had a higher frequency of exacerbations of COPD $(2.1 \pm 0.9$ and $1.7 \pm 1.0$, respectively, $\mathrm{p}<0.001)$. Also in patients with COPD and concomitant GERD there was a higher frequency of hospitalizations $(1.6 \pm 1.0$ and $1.0 \pm 0.9$, respectively, $\mathrm{p}=0.005$ ) (table 1$)$. Correlation analysis revealed a significant relationship between the frequency of GERD and exacerbations of COPD $(r=0.323, p=0.001)$, the severity of bronchial obstruction $(\mathrm{r}=0.331, \mathrm{p}=0.001)$, the frequency of hospitalizations for COPD $(r=0.258, p=0.006)$. However, there was no correlation with the severity of GERD. Patients with COPD with concomitant GERD have a higher frequency of exacerbations. It was found that the severity of bronchial obstruction was higher in patients with concomitant GERD. In addition, a correlation was found between the frequency of GERD symptoms and the severity of bronchial obstruction.

Also in these groups of patients was measured of the function of external respiration (FER) (tabl. 2).

Table 2

Distribution of spirometry values between groups

\begin{tabular}{|l|c|c|}
\hline \multicolumn{1}{|c|}{ Indication } & $\begin{array}{c}\text { Group 1 } \\
\mathbf{n = 6 0}\end{array}$ & $\begin{array}{c}\text { Group 2 } \\
\mathbf{n = 4 2}\end{array}$ \\
\hline FEV 1\% & $63,2 \pm 1,8^{*}$ & $66,1 \pm 1,4$ \\
\hline VC\% & $75,5 \pm 1,2$ & $78,1 \pm 0,7$ \\
\hline FVC \% & $73,3 \pm 1,9^{*}$ & $75,4 \pm 1,7$ \\
\hline FEV1/ FVC ratio \% & $63,2 \pm 0,9^{*}$ & $65,2 \pm 0,7$ \\
\hline FEF25 \% & $40,1 \pm 1,4^{*}$ & $43,3 \pm 1,5$ \\
\hline FEF 50 \% & $34,3 \pm 1,5$ & $36,5 \pm 1,3$ \\
\hline FEF 75\% & $33,2 \pm 1,7^{*}$ & $33,4 \pm 2,0$ \\
\hline
\end{tabular}

Note. Significance of the difference: ${ }^{*}$ - in comparison with patients of group 2 at $p<0,05$.

The processing of spirometry data in patients with combined GERD revealed a significantly more pronounced decrease in the main indicators of external respiration: FEV1, FVC, forced expiratory flow over the middle one half of the FVC ( FEF) 25\%, 50\%, 75\%, FEV1/ FVC ratio compared to normal values in people of the appropriate sex, age, height and body weight (FEV1> 80\%, FEV1 / FVC> 70\%). In the group with combined pathology, FEV1, VL, FVC, FEV1 / FVC, respectively, were $63.2 \pm 1.8,75.5 \pm 1.2,73.3 \pm 1.9,63.2 \pm 0.9 \%$ and made a significant difference $(p<0,05)$ with similar indicators of group 2 (patients with COPD without signs of GERD), in which these indicators averaged 66.1 $\pm 1.4,78.1 \pm 0.7,75.4 \pm 1.7$, $65.2 \pm 0.7 \%$, respectively.

In patients with comorbid pathology of COPD and GERD, a negative correlation was found between age and FVC, age and FEV1 by Pearson's ratio, $p<0,005$. (table 3).

In the study of laboratory indicators of inflammation, the following data were obtained

Patients in groups 1 and 2 showed an increase in acute phase and pro-inflammatory parameters compared with group 3, where all these indicators were within normal limits at $\mathrm{p}<0.05$.

Procalcitonin levels in patients of all groups are not prognostically significant at $p<0.05$. A direct correlation was found between the content of IL-4 and IL-6 $(r=0.60, p<0.05)$. 
Table 3

Evaluation of laboratory parameters in groups

\begin{tabular}{|c|c|c|c|}
\hline Indication & $\begin{array}{c}\text { Group } 1 \\
\mathbf{n}=\mathbf{6 0}\end{array}$ & $\underset{n=42}{\operatorname{Group}} 2$ & $\begin{array}{c}\text { Group } 3 \\
n=36\end{array}$ \\
\hline Leukocytes $10 * 12 / l$ & $12,3 \pm 1,3 *$ & $11,2 \pm 0,8 * *$ & $6,5 \pm 1,3$ \\
\hline Neutrophils \% & $74,1 \pm 2,6$ & $72,2 \pm 2,1$ & $67,2 \pm 3,1$ \\
\hline Lymphocytes \% & $15,2 \pm 2,4$ & $18,2 \pm 1,1$ & $19,2 \pm 1,1$ \\
\hline ESR $\mathrm{mm} /$ year & $18 \pm 3,4^{*}$ & $16 \pm 2,3 * *$ & $6 \pm 4,1$ \\
\hline$C R P m g / l$ & $15,3 \pm 1,8^{*}$ & $14,3 \pm 1,2 * *$ & $3,3 \pm 1,5$ \\
\hline Procalcitonin $\mathrm{ng} / \mathrm{ml}$ & $0,1 \pm 0,03$ & $0,04 \pm 0,02$ & $0,03 \pm 0,01$ \\
\hline$I L-4, p g / m l$ & $12,7 \pm 1,3^{*}$ & $9,8 \pm 1,1 * *$ & $4,1 \pm 0,6$ \\
\hline Interferon gamma $(I F N \gamma) p g / m l$ & $346,2 \pm 13,5^{*}$ & $289 \pm 14,8^{* *}$ & $126,9 \pm 12,4$ \\
\hline$I F N \gamma / I J-4$ & $28,3 \pm 3,2 *$ & $15,1 \pm 4,1 * *$ & $7,1 \pm 1,4$ \\
\hline$I L-6, p g / m l$ & $17,3 \pm 2,2 *$ & $14,3 \pm 2,4 * *$ & $6,8 \pm 1,7$ \\
\hline$T N F-\alpha p g / m l$ & $10,1 \pm 3,4$ & $13,1 \pm 2,5$ & $5,4 \pm 1,4$ \\
\hline
\end{tabular}

Note. Significance of the difference: * - in comparison with patients of group 2 and 3 at $p<0,05$, ** - in comparison with patients of group 1 and 3 at $p<0,05$.

Table 4

Indicators of pepsinogen and bilirubin in the groups

\begin{tabular}{|l|c|c|c|}
\hline \multicolumn{1}{|c|}{ Indication } & $\begin{array}{c}\text { Group 1 } \\
\mathbf{n = 6 0}\end{array}$ & $\begin{array}{c}\text { Group 2 } \\
\mathbf{n = 4 2}\end{array}$ & $\begin{array}{c}\text { Group 3 } \\
\mathbf{n = 3 6}\end{array}$ \\
\hline Pepsinogen-1 in saliva, $\mathbf{n g} / \mathbf{m l}$ & $0,83 \pm$ & $0,22 \pm$ & $0,360,11$ \\
\hline Pepsinogen-1 in saliva, $\mathbf{n g} / \mathbf{m l}$ & $2,26 \pm$ & $1,99 \pm$ & $2,20,70$ \\
\hline Total bilirubin in saliva, $\boldsymbol{\mu m o l} / \mathbf{l}$ & $1,2 \pm$ & $0,91 \pm$ & $0,98 \pm$ \\
\hline
\end{tabular}

Note. Significance of the difference: * - in comparison with patients of group 2 and 3 at $p<0,05$, ** - in comparison with patients of group 1 and 3 at $\mathrm{p}<0,05$

There was a positive relationship between decreased FER levels, namely FVC and FEV1 values, clinical symptoms of COPD, and values of pepsinogen-1, pepsinogen-2 and total bilirubin in saliva. Thus, in patients with COPD found a direct correlation with the presence of shortness of breath (Pearson's ratio, $p=0,011$; ANOVA, $p<0,001$; test

Cruscalla-Wallis, $\mathrm{p}<0.001$;), as well as reduced FEV-1 (Pearson's ratio, $\mathrm{p}<0.001$; t-test, $\mathrm{p}<0.001$; $\mathrm{z}$-score, $\mathrm{p}=0.046$ ).

A comparison of total bilirubin in saliva and FER revealed a statistically significant positive correlation between total bilirubin, on the one hand, and FVC and FEV1 (Pearson's ratio, $\mathrm{p}=0.011$ ) and FEV-1 (Pearson's ratio, $\mathrm{p}=0.044)$. .

The study of the presence of pepsinogen-1 in saliva revealed a statistically significant positive correlation with the presence of smoking (rank correlation coefficient, $\mathrm{p}=0.002$, Mann-Whitney test $\mathrm{p}=0.004$ ) and a negative correlation between FEV1 and FVC (t-test, $\mathrm{p}<0.001$; Pearson, $\mathrm{p}<0.001$ ).

Subsequent analysis revealed that the level of pepsinogen-2 in saliva was positively correlated with clinical symptoms such as cough (rank correlation coefficient, $p=0.012$ ), shortness of breath (rank correlation coefficient, $p=0.026$ ) and smoking (rank correlation coefficient, $\mathrm{p}=0.006$ ), as well as with the frequency of exacerbations per person (Pearson's ratio, $\mathrm{p}=0.027$ ). 
It is noteworthy that the level of total bilirubin in saliva showed a statistically significant positive correlation with the value of pepsinogen-1 in saliva (Pearson's ratio, $p=0.019$; Kruscal-Wallis test, $\mathrm{p}=0.024$ ), and with the value of pepsinogen -2 in saliva (Pearson's ratio, $\mathrm{p}=0,049$.

The study revealed a statistically significant positive correlation of total bilirubin in saliva, on the one hand, and a decrease in FVC, FEV-1, as well as with the presence of shortness of breath.

The value of pepsinogen-1 in oral saliva showed a statistically significant positive correlation with an allergic history, and a negative correlation with the value of FEV1 / FVC ratio.

The level of pepsinogen-2 in saliva showed a positive correlation with symptoms such as cough, shortness of breath and smoking.

A statistically significant positive correlation was found between the levels of total bilirubin and the values of pepsinogen- 1 and pepsinogen- 2 in saliva.

Discussion: Thus, the detection of a negative correlation between age and FVC, age and FEV1 in patients with combined pathology, suggests that the presence of concomitant GERD is an independent aggravating factor for the function of external respiration.

In patients with COPD in combination with GERD, there is a marked increase in acute phase parameters, namely leukocytes, ESR, the level of C-reactive protein, which indicate active systemic inflammation.

Also in this group of patients there is an increase of almost 3 times the level of IFN $\gamma$, which involves the activation of the cellular immune system.

Increased, almost 3 times compared to group 3 control, the ratio between IFN $\gamma$ / IL-4 indicates the presence of an imbalance in the immune system, which is also more pronounced in patients with concomitant GERD.

Also, the increase in the pro-inflammatory cytokine IL- 6 by almost 2 times stimulates an excessive and unregulated immune response, which in turn supports chronic inflammation in the bronchi even in remission.

Increased levels of IL-4 are compensatory in nature, as IL-4 inhibits the production of macrophages of proinflammatory cytokines, including IL-6.

Direct correlation of the concentration of total bilirubin in saliva with a decrease in external respiration, namely FVC, FEV-1, as well as with the presence of shortness of breath allows to consider bilirubin as one of the possible markers of reflux and respiratory inflammation in the bronchial tree, up to obstruction.

A positive correlation of pepsinogen-1 in saliva with an allergic history, and pepsinogen-2 - with symptoms such as cough, shortness of breath and smoking, and a negative correlation of pepsinogen-1 with FEV1 / FVC ratio, allows to consider pepsinogen-1 and pepsinogen-2 as markers of non-acid reflux and respiratory inflammation with bronchoobstruction.

\section{Conclusion}

1. The presence of GERD in patients with COPD is an aggravating factor that increases the frequency of exacerbations in patients with combined pathology.

2. Total bilirubin, pepsinogen-1 and pepsinogen- 2 in saliva should be considered not as separate, but combined markers of duodeno-gastroesophageal and laryngo-pharyngeal reflux and additional causes of inflammation and bronchoobstruction.

3. Determination of pepsinogens 1 and 2 and bilirubin in saliva are non-invasive methods for detecting duodeno-gastroesophageal and laryngopharyngeal reflux in patients with GERD. 


\section{References}

Aras, G., Yelken, K., Kanmaz, D., Develioglu, O., Mavis, O., Gultekin, E., ... \& Purisa, S. (2010). Erosive esophagitis worsens reflux signs and symptoms in asthma patients without affecting pulmonary function tests. Journal of Asthma, 47(10), 1101-1105

Chorna, V. V., Khlyestova, S. S., Gumenyuk, N. I., Makhnyuk, V. M., \& Sydorchuk, T. M. (2020). Pokaznyky zakhvoryuvanosti i poshyrenosti ta suchasni poglyady na profilaktyku khvorob.[ Morbidity indicators and dissemination and modern attitudes on disease prevention]. Visnyk Vinnytskogo natsionalnogo medychnogo universytetu, 24(1), 158-164 [in Ukrainian]

Francis DO.(2016) Chronic cough and gastroesophageal reflux disease. Gastroenterol Hepatol (N Y), 12(1):64.

Golpe, R., Martín-Robles, I., Sanjuán-López, P., Cano-Jiménez, E., Castro-Añon, O., Mengual-Macenlle, N., \& Pérez-de-Llano, L. (2017). Prevalence of major comorbidities in chronic obstructive pulmonary disease caused by biomass smoke or tobacco. Respiration, 94(1), 38-44. Katzka, D. A., Enders, F., Romero, Y., Alexander, J. A., Achem, S. R., Francis, D. L., ... \& Arora, A. S. (2011). Which chronic upper airway symptoms may be due to acid reflux?. Gastroenterology, 5(140):254.

Kusano, M., Kuribayashi, S., Kawamura, O., Shimoyama, Y., Hosaka, H., Nagoshi, A., ... \& Mori, M. (2011). A Review of the management of gastric acid-related diseases: focus on rabeprazole. Clinical Medicine. Gastroenterology, 4, CGast-S5133.

Kravchenko, T. Yu., Losyeva, K. O., Lotysh, N. G., Loseva, E. A., \& Lotysh, N. G. (2011). Gastroezofagealna reflyuksna khvoroba u ditey: etiopatogenez, klinika, diagnostyka ta likuvannya [Gastroesophageal reflux disease in children: etiopathogenesis, clinic, diagnosis and treatment] https://journal.odmu.edu.ua/xmlui/bitstream/handle/123456789/1929/KravchenkoArt. pdf? sequence $=1 \&$ is Allowed $=y$ [in Ukrainian]

Lin YH, Tsai CL, Tsao LI, Jeng C.(2019) Acute exacerbations of chronic obstructive pulmonary disease (COPD) experiences among COPD patients with comorbid gastrooesophageal reflux disease. Journal of clinical nursing, 28(9-10), 1925-1935.

Makarova GV, Rekalova OM.(2019) Osoblyvosti perebigu khronichnogo bronkhitu u khvorykh z suputnoyu gastroezofagalnoyu reflyuksnoyu khvoroboyu [Features of the course of chronic bronchitis in patients with related gastroesophageal reflux disease]. Astma y allergyya, (4):37-42[in Ukrainian]

Pearson, J. P., Parikh, S., Orlando, R. C., Johnston, N., Allen, J., Tinling, S. P., .. \& Belafsky, P. C. (2011). Reflux and its consequences--the laryngeal, pulmonary and oesophageal manifestations. Conference held in conjunction with the 9th International Symposium on Human Pepsin (ISHP) Kingston-upon-Hull, UK, 21-23 April 2010. Alimentary Pharmacology and Therapeutics, 33, 1-71.

Shevchuk-Budz, U. I. (2018). The study of clinical and pathogenetic characteristics of the chronic bronchitis course on the background of the aggravating concomitant gastroesophageal reflux.

Tolokh, O. S. (2017). Xronichne obstruktyvne zakhvoryuvannya legen: novi rishennya starykh problem. Ukrayinskyy pulmonologichnyy zhurnal [Chrjnic obstructive pulmonary disease $e^{\wedge}$ w solution of old problem]. (3), 51-56. [in Ukrainian]

Wang, Y. J., Lang, X. Q., Wu, D., He, Y. Q., \& Lan, C. H. (2020). Salivary pepsin as an intrinsic marker for diagnosis of sub-types of gastroesophageal reflux disease and gastroesophageal reflux disease-related disorders. Journal of neurogastroenterology and motility, 26(1), 74.

Ye, B. X., Jiang, L. Q., Lin, L., Wang, Y., \& Wang, M. (2017). Reflux episodes and esophageal impedance levels in patients with typical and atypical symptoms of gastroesophageal reflux disease. Medicine, 96(37). 